\title{
The Definition of Obesity
}

\author{
Soo Young Kim \\ Department of Family Medicine, Kangdong Sacred Heart Hospital, Hallym University College of Medicine, Seoul, Korea
}

The World Health Organization (WHO) Regional Office for the Western Pacific Region has suggested body mass index (BMI) standards that differ from those used in Europe and North America: normal, 18.5-22.9 kg/m²; overweight, 23-24.9 kg/m² moderate obesity, $25-29.9 \mathrm{~kg} / \mathrm{m}^{2}$; and severe obesity, $\geq 30 \mathrm{~kg} /$ $\mathrm{m}^{2}$. ${ }^{1)}$ The Korean Society for the Study of Obesity has adopted this definition. ${ }^{2)}$ Recently, there has been controversy over the definition of obesity, as some medical professionals feel that this standard is too low.

In the present issue, Yu et al. ${ }^{3)}$ evaluated the association between BMI and mortality according to sex in a communitydwelling elderly population. The authors obtained the data from "Living Profiles of Older People Surveys," which comprised 10,613 community-dwelling South Korean men and women aged 65 years or older. The authors found that the highest survival rates were observed in men with a BMI of $25.0-29.9 \mathrm{~kg} / \mathrm{m}^{2}$; a similar trend was observed in women, but this was not statistically significant. These results are similar to findings from previous research, which reported that in cohorts of East Asians, including Chinese, Japanese, and Koreans, the lowest risk of death was seen among persons with a BMI of 22.6 to $27.5 \mathrm{~kg} / \mathrm{m}^{2}$. $)$

The cut-offs used for the definition of obesity are based on excess morbidity and mortality associated with increasing BMI. ${ }^{1)}$ There is a significantly increased risk of type 2 diabetes mellitus and hypertension among those with a BMI of 23 to 24.9 , as compared to those within the normal range. ${ }^{4)}$ In a prospective cohort study of Koreans, the death rate from any cause had a J-shaped association with the BMI. ${ }^{5)}$

Therefore, the definition of obesity in Koreans may be different, depending on whether the definition is based on mortality rate or morbidity rate, and it may be the cause of con- troversy. The WHO Regional Office for the Western Pacific Region also pointed out that the recommendations were provisional and must be revised in the light of further validation studies and clinical experience. ${ }^{1)}$

This study should cause rethinking of the definition of obesity in Korea, and there should be a serious discussion based on these results.

\section{CONFLICT OF INTEREST}

No potential conflict of interest relevant to this article was reported.

\section{REFERENCES}

1. World Health Organization Western Pacific Region. The AsiaPacific perspective: redefining obesity and its treatment [Internet]. Geneva: World Health Organization; 2000 [cited 2016 Nov 3]. Available from: http://www.wpro.who.int/nutrition/ documents/Redefining_obesity/en/.

2. Kim MK, Lee WY, Kang JH, Kang JH, Kim BT, Kim SM, et al. 2014 clinical practice guidelines for overweight and obesity in Korea. Endocrinol Metab (Seoul) 2014;29:405-9.

3. Yu SY, Kim BS, Won CW, Choi H, Kim S, Kim HW, et al. Body mass index and mortality according to sex in a communitydwelling elderly population: the 3-year follow-up findings from the living profiles of older people surveys in Korea. Korean J Fam Med 2016;37:317-22.

4. Zheng W, McLerran DF, Rolland B, Zhang X, Inoue M, Matsuo $\mathrm{K}$, et al. Association between body-mass index and risk of death in more than 1 million Asians. N Engl J Med 2011;364:719-29.

5. Jee SH, Sull JW, Park J, Lee SY, Ohrr H, Guallar E, et al. Bodymass index and mortality in Korean men and women. $\mathrm{N}$ Engl J Med 2006;355:779-87. 